\title{
Asthma: Its impact, classification, diagnosis, and treatment
}

\author{
Sandra N. González-Diaz* \\ Regional Center of Allergy and Clinical Immunology, University Hospital "Dr. José Eleuterio González", Monterrey, Nuevo Leon, Mexico
}

\begin{abstract}
Asthma is a chronic inflammatory disease that is associated with hyperreactivity of the airway, recurrent episodes of wheezing, difficulty breathing, chest tightness, and coughing. Asthma represents significant direct and indirect costs originating from patient care with poor control of the disease, as a result in many cases, of a bad diagnosis and therefore bad treatment. Asthma not only increases health care and medical costs but it also affects the quality of life of patients and their families. The factors considered as the basis for the increase in asthma are varied, and interact differently between the populations studied. At present, there are different endotypes, genotypes, and phenotypes of asthma. The diagnosis of asthma is clinical, but there are diagnostic tools to evaluate the main functional alterations of asthma, such as airflow obstruction, reversibility, variability, and bronchial hyperreactivity. It is necessary to make a joint effort to reduce the rate of morbidity, disability, and premature deaths due to chronic respiratory diseases. Educational programs for health-care providers as well as parents are essential to achieve a timely detection and therefore establish the ideal treatment for each patient.
\end{abstract}

Key words: Asthma. Phenotypes. Bronchial hyperreactivity.

\section{Introduction}

In 2019, the global initiative for asthma described asthma as a chronic inflammatory disorder linked to hyperreactivity of the airways, leading to recurrent episodes of wheezing, difficulty in breathing, thoracic oppression, and coughing. These episodes are associated with a variable obstruction either of airflow, which is often reversible, spontaneously, or through treatment ${ }^{1}$.

\section{Current asthma impact}

Asthma prevalence is very variable among the different countries around the world. However, reports suggest an increase in asthma prevalence, as well as in other allergic diseases, in low- and middle-income countries which are adopting a more "Westernized" lifestyle ${ }^{2}$. The World Health Organization (WHO) estimates that over 330 million people suffer from asthma worldwide ${ }^{3}$. Asthma represents both a direct and an indirect significant cost derived from the care of patients with an improper control of their disease, which in many cases are a consequence of a wrong diagnosis and an incorrect treatment.

The international study of asthma and allergies in childhood is the most significant collaborative study worldwide and studies the prevalence of allergic diseases and asthma. This study included 2 million children from over 100 countries $^{4}$. In Monterrey, Nuevo Leon, the current and accumulated asthma prevalence found was $8.4 \%$ and $20.5 \%$ in children of 6 and 7 years of age, respectively, while in the group of 13 and 14 years old it was $6 \%$ and $12.6 \%$, respectively ${ }^{5}$.

The economic impact of asthma on society is significant. The related costs of asthma attention are considerable; they affect the economic base of health

\footnotetext{
Correspondence:

*Sandra N. Gonzalez-Diaz

E-mail: sgonzalezdiaz@yahoo.com

Date of acceptance: 19-05-2020

DOI: 10.24875/RMU.20000017

Available online: $30-10-2020$

Medicina Universitaria. 2020;22(3):101-106 www.medicinauniversitaria.org (http://creativecommons.org/licenses/by-nc-nd/4.0/).
} 
services and have a great impact on the economy of families. With an estimated generated cost of 1.2 million dollars, 58\% represents direct costs (hospitalization, treatment at emergency services, medical consultations, and medications) and $42 \%$ are indirect costs (loss of work or school days and early deaths caused by asthma). Asthma not only increases healthcare and medical costs but also affects the quality of life of patients and their families. The asthma insight and reality in Latin America survey, which was conducted on 2184 adults with asthma and parents of children with asthma in 11 countries in Latin America, found that $79 \%$ of adults and $68 \%$ of children limit their daily activities in one way or another as a consequence of asthma ${ }^{6}$.

\section{Factors that influence the expression of asthma}

The factors considered as base in the rise of asthma are varied, and interact in different forms between studied populations. There is a strong genetic base for susceptibility to developing asthma; however, it is well documented that environmental factors have a high impact on asthma prevalence. Among these factors are dietary habits, air pollution, exposure to certain chemicals in the environment, microbial exposure and infection by virus, smoking, economic factors, and changes in housing type, interior environment, and climate changes?

\section{Asthma classification}

- Phenotype, endotypes, genotypes

- Severity

- Control levels.

To perform the classification, the following parameters are taken into consideration:

- Symptom control: controlled, partially controlled, or not controlled.

- Future risk: predicted by the forced expiratory volume in $1 \mathrm{~s}$ (FEV1) and other factors that increase the risk of exacerbations.

- Severity: persistent or intermittent.

- Asthma phenotypes:

- Allergic asthma: early-age onset, family or personal background of atopy.

- Non-allergic asthma: eosinophilic, neutrophilic, or paucigranulocytic with a regular response to treatment with corticosteroids (Competitive Enterprise Institute [CEI]).

- Late-onset asthma: adult women with a poor response to CEI.
- Asthma with obesity: clinical picture without eosinophilia.

- Asthma with fixed limitation to airflow: remodeling, there is no reversibility ${ }^{8}$.

\section{Physiopathology of asthma: inflammation and remodeling of the airways}

Previously, asthma was considered a disease that was only measured by immunoglobin $\mathrm{E}(\mathrm{lg} E)$. Today, there are different asthma endotypes, genotypes, and phenotypes ${ }^{9,10}$. Asthma endotypes describe the different pathophysiological mechanisms at a cellular and molecular level. Despite similar clinical symptoms, patients can respond differently to the same therapeutic interventions. Precision medicine is used to describe treatment directed at the patient's endotype ${ }^{11}$. There are over 200 genes $^{12}$ linked to asthma, as well as multiple factors which take part in its development and variability, making asthma a complex condition, where the inflammatory and remodeling processes are critical components ${ }^{12}$.

The loss of integrity of the bronchial epithelium contributes to the pathogenesis of asthma. This initial damage generates the activation of different resident cells of the bronchial epithelium, mastocytes, alveolar macrophages, and antigen-presenting cells. These release chemical mediators that generate the recruitment and infiltration of the airways by circulating cells such as eosinophils, monocytes, neutrophils, and $\mathrm{T}$ lymphocytes, TH2 > TH1, and Th17. Secondary activation of these cells releases multiple pro-inflammatory cytokines (interleukin [IL]-4, IL-5, IL-6, IL-9, IL-11, IL-12, IL-13, and IL-17), active oxygen radicals and growth factors. These will cause damage and known tissue changes in patients with asthma: hypertrophy of the smooth muscle layer at a bronchial level, thickening of the reticularis sheet, and hypertrophy, and hyperplasia of the sub mucosae glands. This generates a greater production of mucus, microvascular vasodilation, angiogenesis, subepithelial edema, and extracellular matrix remodeling ${ }^{12}$.

\section{Clinical picture}

Patients with asthma present characteristically recurrent symptoms as a result of the obstruction of the airways and bronchial hyperactivity, causing dyspnea, cough, wheezing, and thoracic oppression. These symptoms are variable, with nocturnal or early morning predominance, and can wake the patient up. Cough as an asthma variant can be the only manifestation in up to $15 \%$ of cases ${ }^{1}$. Asthma symptoms can be triggered 
or exacerbated with viral infections, as well as exposure to environmental allergens such as dust mites, animal epithelium, cockroaches, mold, and pollens. Furthermore, irritants include cigarette smoke, chemicals, pollution, climate change, exercise, emotional stress, and menstrual cycles, among others ${ }^{13}$. Wheezing is the most characteristic sign on physical examination; however, its absence does not mean it rules out the disease. In addition, it is recommended to perform an objective test of the obstruction of the airways and the level of reversibility through pulmonary function tests ${ }^{14}$.

\section{Diagnosis}

The diagnosis of asthma is clinical ${ }^{1}$. A detailed clinical history ought to be conducted highlighting personal history and a family background of atopy, characteristics of daytime and night-time symptoms, seasonal change, precipitating or triggering factors, and home and work environmental factors, among others ${ }^{15}$. During physical examination, signs which can increase the probability of asthma diagnosis can be found. At the upper airways level, physicians search for nasal inflammation data, pale nasal mucous, hyaline secretion, hypertrophic turbinates, and presence or absence of nasal polyps. At a thoracic level, the presence of wheezing during normal breathing or an increase of the expiratory phase, with thorax hyperextension and in case of exacerbations, there may be signs of difficulty breathing, nasal flaring, and use of accessory muscles, intercostal retraction, thoracoabdominal dissociation, and cyanosis ${ }^{1}$.

\section{Tests for asthma diagnosis and monitoring}

The main functional alterations of asthma are the obstruction of air flow, reversibility, variability, and bronchial hyperresponsiveness ${ }^{14}$. Spirometry is recommended as the objective pulmonary function study to determine the obstruction of the airways and the patients' degree of reversibility for children $\geq 5$ years of age and adults with asthma. It is the first-choice diagnostic test and is recommended for all patients with a suspicion of asthma ${ }^{1-14}$. The main parameters that should be determined are forced vital capability (FVC) and FEV1. Obstruction is defined by a FEV1/FVC coefficient under 0.7 ; reversibility is evaluated $15 \mathrm{~min}$ after inhalation of $400 \mathrm{mcg}$ of salbutamol with a holding chamber, an increase of $\geq 12 \%$ for FEV1 and $200 \mathrm{ml}$ higher than the base value is considered positive responses.
Variability of pulmonary function through time is essential for asthma diagnosis and control. The most recommended daily variability index is peak expiratory flow rate in relation to the median during a minimum of 1-2 weeks. A variability of FEP higher than $20 \%$ results in a diagnosis of asthma'.

In patients with clinical suspicion of asthma with a normal pulmonary function test, the bronchial hyperresponse degree must be evaluated with the use of methacholine, histamine, mannitol or hypertonic saline solution, and determining the dose or concentration that produces a reduction of $20 \%$ in FEV 1 in relation to the base value. This is a high-sensitivity but low specificity test ${ }^{1,14}$. Fractional exhaled nitric oxide measures the eosinophilic inflammation of the airways in a non-invasive way and is a high-sensitivity and specificity test for the diagnosis of asthma in non-smoking patients, especially if associated with a reduced FEV1. Due to the strong association of asthma with allergic rhinitis and other atopic diseases, it is important to determine the status of the patient through the determination of specific IgE using skin tests or serum determination. The correlation of the exposure with the presence of symptoms should be confirmed with clinical history?

\section{Diagnostic challenges and differential diagnosis}

A differential diagnosis ought to be considered in patients who present recurrent episodes of wheezing and cough and in those patients that do not respond as expected to treatment. Other conditions that involve the lower airways, that is, viral bronchiolitis, bronchitis obliterans, cystic fibrosis, bronchopulmonary dysplasia, and cardiopathies, should be considered. Other causes of recurrent wheezing are aspiration events secondary to alterations of swallowing mechanisms and illnesses due to gastroesophageal reflux. In adult patients, it is necessary to perform a differential diagnosis with chronic obstructive pulmonary disease, congestive cardiac failure, pulmonary embolisms, tuberculosis, mechanical obstruction of the airways secondary to tumors, eosinophilic pulmonary diseases, and cough secondary to the use of medications $s^{1,6,13-15}$.

\section{Treatment}

The objectives of asthma treatment include (Fig. 1):

Several components are required to reach and maintain control of asthma: evaluation and monitoring, 


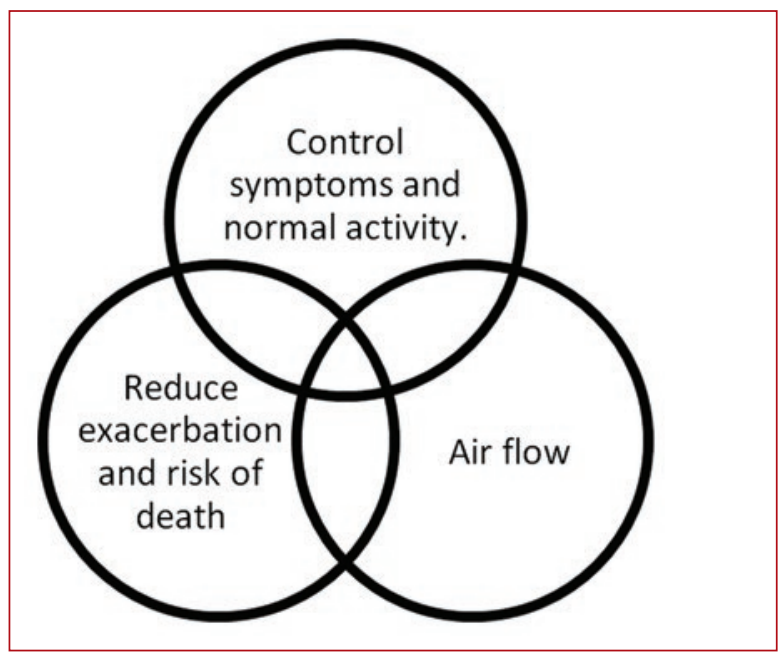

Figure 1. The objectives of asthma treatment.

Table 1. Initial asthma control treatment ${ }^{1}$

\section{Initial control treatment}

ICS should begin as soon as possible.

Indications for the beginning of treatment according to the patient's age and condition.

Fractional exhaled nitric oxide $>50 \mathrm{ppb}$ in non-smokers, linked to a positive short-term response to ICS.

A low dose of corticosteroids is recommended for patients with asthma, even with infrequent symptoms.

Evaluating factors related to an incorrect control (technique, comorbidities, etc.).

ICS: Inhaled corticosteroids

patient education and that of his/her relatives, control of environmental factors and comorbidities that affect asthma, as well as the use of medications. Pharmacological treatment begins based on the severity of asthma and adjusts based on the control of asthma ${ }^{1,13}$ (Table 1).

Inhaled corticosteroids are the cornerstone in the long-term control and treatment of asthma, since it reduces symptoms and improves quality of life as well as pulmonary function, reduces bronchial hyperreactivity, controls inflammation of the airways, reduces the frequency and severity of exacerbations, and reduces mortality by asthma ${ }^{1,16}$ (Table 2).

Different asthma phenotypes can have different degrees of responses to conventional medications, hence, today; the tendency is to direct management based on a specific phenotype treatment, with a better clinical response. Anti-IgE therapy with omalizumab is a good option for the treatment of patients with severe asthma of the allergic type, one that is not controlled despite the use of high doses of inhaled glucocorticoids $^{17}$. Allergen-specific immunotherapy in patients with asthma reduces symptoms, the need for the use of medications, and improves bronchial hyperresponsiveness ${ }^{18}$. Recently, the introduction of anti-IL-5s like mepolizumab has been used in eosinophilic phenotype asthma, to block the maturing and release of eosinophils with positive results in selected patients ${ }^{16}$. Other monoclonal antibodies like dupilumab are inhibitors of the alpha subunit of the IL-4 receptor, which blocks IL-4 and IL-3.

\section{Prognosis}

In general, an asthma prognosis is favorable in most patients; however, there is a small group of patients with severe asthma who do not respond adequately to regular treatment, and their prognosis is uncertain and sometimes fatal ${ }^{19}$. Patients with severe asthma attend emergency services 15 times more often and require hospital admission 20 times more often compared to patients with mild or moderate asthma ${ }^{19}$. According to the $\mathrm{WHO}$, around 250,000 people die each year as a result of asthma ${ }^{3}$. Therefore, in a joint effort, programs of prevention and control of respiratory diseases have been implemented. The education of the population in general, as well as physicians, patients and their families, is a crucial factor to prevent mortality by asthma.

\section{Preventative and educational measures}

On March 28, 2006, the WHO officially launched the global alliance against respiratory diseases in Beijing, China, to support countries in an effort to reduce morbidity rates, disabilities, and premature deaths due to chronic respiratory diseases, especially asthma and $\mathrm{COPD}^{3}$. There are different initiatives worldwide from the different medical associations that promote education and awareness in the medical community, as well as the general population, through the celebration of world asthma day, as well as the dissemination of guidelines based on evidence for its management. Other interventions are aimed at avoiding allergic awareness and the development of asthma in patients who are already sensitized, avoiding exposure to cigarette smoke, occupational agents, irritants, and other known factors that 
Table 2. Asthma management for adults and adolescents. Control of symptoms and descreasing asthma exacerbations

\begin{tabular}{|c|c|c|}
\hline Step & Adults, adolescents & 6-11 years old \\
\hline Step 1 & $\begin{array}{l}\text { As-needed low dose ICS + formoterol } \\
\text { Optional: Low dose ICS taken whenever SABA is taken } \\
\text { Reliever: As-needed low dose ICS + formoterol } \\
\text { SABA }\end{array}$ & $\begin{array}{l}\text { Controller: Low dose ICS taken whenever } \\
\text { SABA is taken or daily low dose ICS } \\
\text { Reliever: SABA }\end{array}$ \\
\hline Step 2 & $\begin{array}{l}\text { Controller: Daily low dose ICS or with LABA (formoterol) when needed } \\
\text { Controlling option: leukotriene receptor antagonista (LTRA) } \\
\text { or ICS + SABA } \\
\text { Reliever: Low dose ICS- formoterol }\end{array}$ & $\begin{array}{l}\text { Controller: Daily low dose ICS } \\
\text { Optional: LTRA or low dose ICS+SABA } \\
\text { Reliever: SABA }\end{array}$ \\
\hline Step 3 & $\begin{array}{l}\text { Controller: Low dose ICS+ LABA } \\
\text { Optional: Medium dose ICS or Low dose ICS+ LTRA } \\
\text { Reliever: ICS+formoterol when needed }\end{array}$ & $\begin{array}{l}\text { Controller: Low dose ICS+LABA or medium } \\
\text { dose ICS } \\
\text { Optional: LTRA+Low dose ICS } \\
\text { Reliever: SABA }\end{array}$ \\
\hline Step 4 & $\begin{array}{l}\text { Controller: Medium dose ICS+LABA } \\
\text { Optional: High dose ICS, Tiotropium, LTRA } \\
\text { Reliever: Low dose ICS+LABA }\end{array}$ & $\begin{array}{l}\text { Controller: Medium dose ICS+LABA and refer } \\
\text { to specialist } \\
\text { Optional: High dose ICS+LABA or add LTRA } \\
\text { or tiotropium } \\
\text { Reliever: SABA }\end{array}$ \\
\hline Step 5 & $\begin{array}{l}\text { Identify phenotype } \\
\text { Biological treatment (Anti IgE, Anti-IL-5, IL-4R) } \\
\text { Optional: Oral corticosteroids } \\
\text { As needed low dose ICS+formoterol for patients prescribed maintenance } \\
\text { and reliever therapy } \\
\text { SABA }\end{array}$ & $\begin{array}{l}\text { Identify phenotype } \\
\text { Biological treatment: Add on Anti IgE } \\
\text { Optional: Oral corticosteroids }\end{array}$ \\
\hline
\end{tabular}

trigger symptoms (allergens, infections, and pollutants). The physician must provide scientific information, supervised training on the use of devices and how to perform asthma monitoring; it is important to set goals for the treatment and provides a written plan of action reinforcing all the information on every visit ${ }^{19-21}$. Special attention must be given through educational program on asthma in the work place, at school, nurseries, and sporting areas, to name a few ${ }^{1}$. At the regional center of allergies and clinical immunology of the "Dr. José E. González" University Hospital, the asthma club camp has taken place for the past 32 years, with over 13,000 children with asthma and other allergic diseases, as well as their families. During their stay, educational talks are given to the parents, imparted by certified allergists, while the children perform activities that include exercises indicated specially for those patients with chronic respiratory diseases. Multidisciplinary management is essential for an integral treatment of patients with asthma.

\section{Conflicts of interest}

The authors declare that they have no conflicts of interest.

\section{References}

1. GINA Report, Global Strategy for Asthma Management and Prevention 2019 Definition, Description, and Diagnosis of Asthma; 2019. Available from: https://www.ginasthma.org/wp-content/uploads/2019/06/GINA2019-main-report-June-2019-wms.pdf.

2. Bousquet J, Khaltaev N. Global surveillance, prevention and control of chronic respiratory diseases: a comprehensive approach. In: Global Alliance Against Chronic Respiratory Diseases. Geneva: World Health Organization; 2007.

3. Asher MI, Montefort S, Bjorksten B, Lai CK, Strachan DP, Weiland SK, et al. Worldwide time trends in the prevalence of symptoms of asthma, allergic rhinoconjunctivitis, and eczema in childhood: ISAAC phases one and three repeat multicountry cross-sectional surveys. Lancet. 2006; 368:733-43.

4. Pawankar R, Canonica GW, Holgate ST, Lockey RF. WAO White Book on Allergy. Ch. 2:2.1. United States: Burden on Allergy Diseases; 2011. p. 27-30.

5. Asher MI, Montefort S, Björksten B, Lai CK, Strachan DP, et al. Worldwide time trends in the prevalence of symptoms of asthma, allergic rhinoconjunctivitis, and eczema in childhood: ISAAC phases one and three repeat multicountry cross-sectional surveys. Lancet. 2006;368(9537):733-43.

6. Neffen H, Gonzalez SN, Fritscher CC, Dovali C, Williams AE. The burden of unscheduled health care for asthma in Latin America. J Investig Allergol Clin Immunol. 2010;20:596-601.

7. Wahn U. Allergy Frontiers: epigenetics, Allergens and Risk Factors. $1^{\text {st }}$ ed. Japan: Springer; 2009. p. 3-15.

8. Larenas-Linnemann D, Salas-Hernández J, Vázquez-Garcia JC, Ortiz-Aldana I, Fernández-Vega M, Del Río-Navarro BE, et al. Guia Mexicana del asma: GUIMA 2017. Rev Alerg Mex. 2017;64:s9-10.

9. Peat JK, Woolcock AJ. Sensitivity to common allergens: relation to respiratory symptoms and bronchial hyper-responsiveness in children from three different climatic areas of Australia. Clin Exp Allergy. 1991;21: 573-81.

10. Desmond M, Murphy MB, O'Byrne PM. Recent advances in the pathophysiology of asthma. CHEST. 2010:137:1417-26.

11. Gupta J, Johansson E, Bernsten JA, Chakraborty R, Hershery GJ, Rothenberg ME, et al. Resolving the etiology of atopic disorders by using genetic analysis of racial ancestry. J Allergy Clin Immunol. 2016; 138:676-99. 
12. National Asthma Education and Prevention Program. Expert panel report 3 (EPR-3): guidelines of the diagnosis and management of asthma-summary report 2007. J Allergy Clin Immunol. 2007;120:S94-138.

13. Atkinson RW, Anderson HR, Sunyer J, Baccini JA, Vonk JM, Boumghar A, et al. Acute effects of particulate air pollution on respiratory admissions: results from APHEA 2 project. Air pollution and health: a European approach. Am J Respir Crit Care Med. 2001;164:1860-6.

14. Kuruvilla M, Eun-Hyung L, Lee G. Understanding asthma phenotypes, endotypes, and mechanisms of disease. Clin Rev Allergy Immunol. 2019;56:219-33

15. Lotvall J, Akdis CA, Bacharier LB, Bjermer L, Casale TB, Custovic A et al. Asthma endotypes: a new approach to classification of disease entities within the asthma syndrome. Allergy Clin Immunol. 2011;127:355-60.

16. Adkinson N, Busse W, Bochner B, Holgate S, Simons FE, Lemanske R Middleton's Allergy: principles and Practice. $7^{\text {th }}$ ed. China: Mosby Elsevier; 2009. p. 893-920.
17. Bousquet J, Khaltaev N, Cruz AA, Denburg J, Fokkens WJ, Togias A et al. Allergic rhinitis and its impact on asthma (ARIA) 2008 update (in collaboration with the World Health Organization, GA2LEN and AllerGen). Allergy. 2008:63:8-160

18. British Thoracic Society. British Guideline on the Management of Asthma. A National Clinical Guideline. [cited 12 December 2019]. Available from: http://www.brit-thoracic.org.uk.

19. Bacharier LB, Phillips BR, Zeiger RS, Szefler SJ, Martinez FD, Lemanske RF Jr., et al. Episodic use of an inhaled corticosteroid or leukotriene receptor antagonist in preschool children with moderate-to-severe intermittent wheezing. J Allergy Clin Immunol. 2008:122:1127-35.

20. Fernández-Benitez M, Gómez-Ruíz F, López-Viña A, Molina-París J, Navarro-Rubio D, et al. Guía Española Para el Manejo del Asma. Germany: GEMA; 2009. p. 1-114.

21. Gonzalez-Diaz S, Gallego-Corella Cl, Galindo-Rodriguez G, Leal-Villarreal L, Arias-Cruz A, Buenfil-López JS. Asthma and pregnancy-comorbid and coexisting. GARJMMS. 2012;1:292-303 